\title{
A MODEL FOR SIMULTANEOUS DECISIONS ON MASTER PRODUCTION SCHEDULING, LOT SIZING, AND CAPACITY REQUIREMENTS PLANNING
}

\author{
Harish C. Bahl, California State University-Chico,hbahl@csuchico.edu \\ Neelam Bahl, California State University-Chico,nbahl@csuchico.edu
}

\begin{abstract}
Traditionally, decisions on master production scheduling, material requirements planning, and capacity requirements planning have been made sequentially, resulting in iterative loops that are often time-consuming and inefficient. In this paper, a linear programming model provides a methodology for making these decisions simultaneously. Beginning with the variables of master production scheduling, material requirements planning is carried out using these variables. It was assumed that the period order quantity lot sizing method would be used to determine lot sizes for different components at various levels within the bills of materials. Capacity requirements planning for the planned orders is then carried out providing efficient solutions for master production scheduling, lot sizing, and capacity requirements.
\end{abstract}

Keywords: Material requirements planning, Linear programming and Information technology

\section{INTRODUCTION}

Manufacturing planning in organizations is typically carried out using a hierarchical model [2]. Normally, sales and operations (SOP) plans are based upon the data obtained from demand management. These SOP plans are then disaggregated into master production schedules (MPS) for individual products; this, in turn, drives material requirements planning (MRP) for raw materials, components, and subassemblies. The feasibilities of SOP, MPS, and MRP are evaluated to ensure capacities are available when needed.

Figure 1 illustrates how these decisions are made in a sequential manner within a hierarchical model. In order to ensure these decisions are consistent and feasible, they are linked with feedback and iterative loops. MRP decisions are evaluated and revised by means of capacity requirements planning. MPS decisions are evaluated and updated by means of rough-cut capacity planning. If MRP decisions are found unfeasible, this may lead to revisions in MPS decisions.

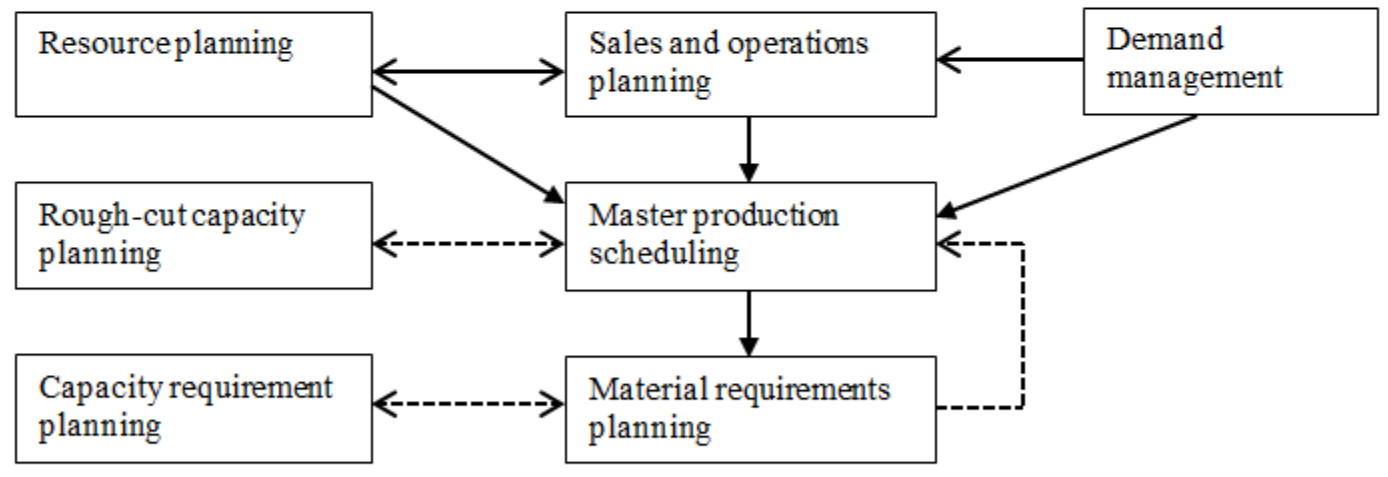

FIGURE 1. A Hierarchical Model of Decision Making

Sequential and iterative decision making in manufacturing planning can cause planners and managers to expend a great deal of time and energy, and the resulting decisions are likely to be suboptimal and inefficient. In this paper, a linear programming model is developed to help managers make decisions relative to MPS, MRP (including lot sizing), and capacity requirements planning simultaneously, which in turn will eliminate the need for sequential and iterative steps in making these decisions. MPS, MRP, and capacity requirement planning are all implemented on computer systems with the help of software such as SAP [4]. The proposed linear programming model can be 


\section{Issues in Information Systems}

Volume 14, Issue 2, pp.353-358, 2013

embedded in the software to enable managers to make these decisions efficiently without trial and error. Information technology resources such as the database in SAP and the computational resources needed for linear programming are thus deployed optimally.

The simultaneous decisions model is developed in the next section. The model starts with MPS variables related to MPS unknown quantities, and it carries out MRP calculations in terms of MPS variables. The MRP results of planned production orders then become the variables in the linear programming model. The assumptions of the model and its mathematical formulation are also discussed. A sample problem is then provided to illustrate the proposed model. The linear programming formulation of the model and its solution are presented. In the conclusion section, the application of the model to the industry is discussed. Benefits of the model related to teaching manufacturing planning concepts to supply chain management students are also presented in the conclusion of the paper.

\section{PROPOSED SIMULTANEOUS DECISIONS MODEL}

Several important factors were considered in developing the model. First, the model begins with the variables of unknown production quantities for various products in the MPS. Calculations for MRP with bills of materials, lot sizing, and lead times are carried out in terms of these MPS variables. Planned orders generated by MRP, in terms of the MPS variables, are then input into capacity requirements planning.

Second, the period order quantity lot sizing (POQ) method is used in the MRP calculations. Results of research studies $[1,3]$ indicate that POQ is a good heuristic method for lot sizing calculations in MRP, and it was found to be superior to such heuristic methods as economic order quantity, lot-for-lot, and least unit cost. Based upon an estimate of the annual demand for a component and other cost data related to the component, the number of periods in POQ lot sizing is calculated by rounding off the quotient of economic order quantity divided by the estimated demand.

Finally, it was assumed that MPS decisions are made beyond the planning fence in the planning horizon. It is common industry practice $[4,5]$ to freeze initial periods of MPS covering the product lead time in the rolling planning horizon. For example, MPS is planned on the first of January for the periods April 1 to September 30 for a product with a lead time of three months and planning horizon of six months.

The simultaneous decisions model is formulated and shown below. A sample problem is solved using this model in the next section. The objective function minimizes the sum of inventory carrying costs for end-items, regular time costs at all work centers, and overtime costs. Capital letters denote model variables and lower-case letters denote the constants or known coefficients in the model.

Minimize $\quad \mathrm{Z}=\sum \sum \mathrm{I}_{\mathrm{it}} \cdot \mathrm{c}_{\mathrm{it}}+\sum \sum \mathrm{E}_{\mathrm{kt}} \cdot \mathrm{a}_{\mathrm{kt}}+\sum \sum \mathrm{F}_{\mathrm{kt}} \cdot \mathrm{b}_{\mathrm{kt}}$

Subject to

$\begin{array}{cc}\mathrm{I}_{\mathrm{it}}-\mathrm{I}_{i, t-1}+\mathrm{X}_{i t}=\mathrm{d}_{\text {it }} & \mathrm{i} \in \mathrm{M} \\ & \mathrm{t} \in \mathrm{T}\end{array}$

$\mathrm{N} M$

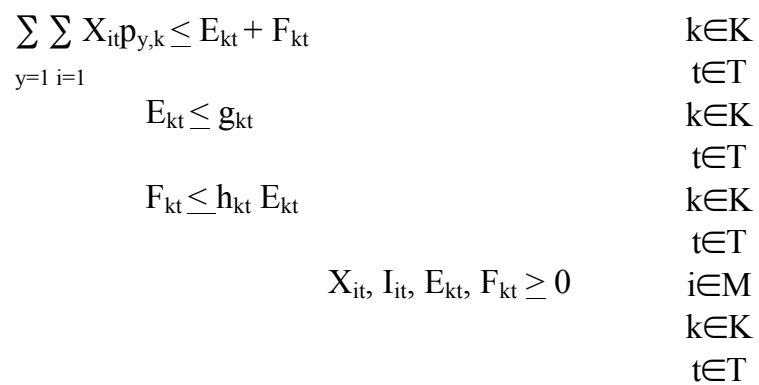


The notations used in the model are described below:

$\mathrm{N} \quad$ Set of all items including end-items, subassemblies and components in the bill of materials.

$\mathrm{M} \quad$ Set of all end-items (or products).

K Set of work centers.

$\mathrm{T} \quad$ Set of time-periods in the planning horizon.

$\mathrm{I}_{\mathrm{it}} \quad$ Amount of inventory for product $\mathrm{i}$ at the end of period $\mathrm{t}$.

$\mathrm{X}_{\mathrm{it}} \quad$ Master production schedule quantity for product $\mathrm{i}$ during period $\mathrm{t}$.

$\mathrm{E}_{\mathrm{kt}} \quad$ Regular time capacity in hours used by work center $\mathrm{k}$ in period $\mathrm{t}$.

$\mathrm{F}_{\mathrm{kt}} \quad$ Overtime capacity in hours used by work center $\mathrm{k}$ in period $\mathrm{t}$.

$\mathrm{c}_{\mathrm{it}} \quad$ Inventory carrying cost for product $\mathrm{i}$ at the end of period $\mathrm{t}$.

$a_{k t} \quad$ Regular time cost per hour for work center $\mathrm{k}$ in period $\mathrm{t}$.

$b_{k t} \quad$ Overtime cost per hour for work center $\mathrm{k}$ in period $\mathrm{t}$.

$\mathrm{d}_{\mathrm{it}} \quad$ Demand for product $\mathrm{i}$ in period $\mathrm{t}$.

$h_{k t} \quad$ Fraction of regular hours of work center $k$ in period $t$ so that $h_{k t} E_{k t}$ gives the upper limit on overtime hours.

$\mathrm{p}_{\mathrm{yk}} \quad$ Total operation time (processing time and setup time) required by component $\mathrm{y}$ on work center $\mathrm{k}$ making one unit of product in period due to period order quantity lot-sizing..

Constraint set (2) represents the inventory balance constraints. Constraint set (3) requires that the capacity hours used by all the components at a work center should not exceed the regular time and overtime available at the work center. The left-hand side shows the total work load resulting from all the planned orders in a work center within a given period. Constraint set (4) imposes an upper limit on regular-time capacity, whereas (5) restricts the overtime to a fraction of the regular time available at a work center.

\section{A SAMPLE PROBLEM FORMULATION AND ITS SOLUTION}

In order to illustrate the concepts and the proposed model, a simple problem is shown in Figure 2 and Table 1 assuming some relevant data for the products, components, and resources. The linear programming model was formulated and solved with the EXCEL-solver software. In this problem, there are two products (PROD1 and PROD2) and each has only one component (COMP1 for PROD1 and COMP2 for PROD2). The number of periods in POQ is already calculated based upon estimated annual demand and computing economic order quantity. Lead time (LT) is also assumed to be known for each item.

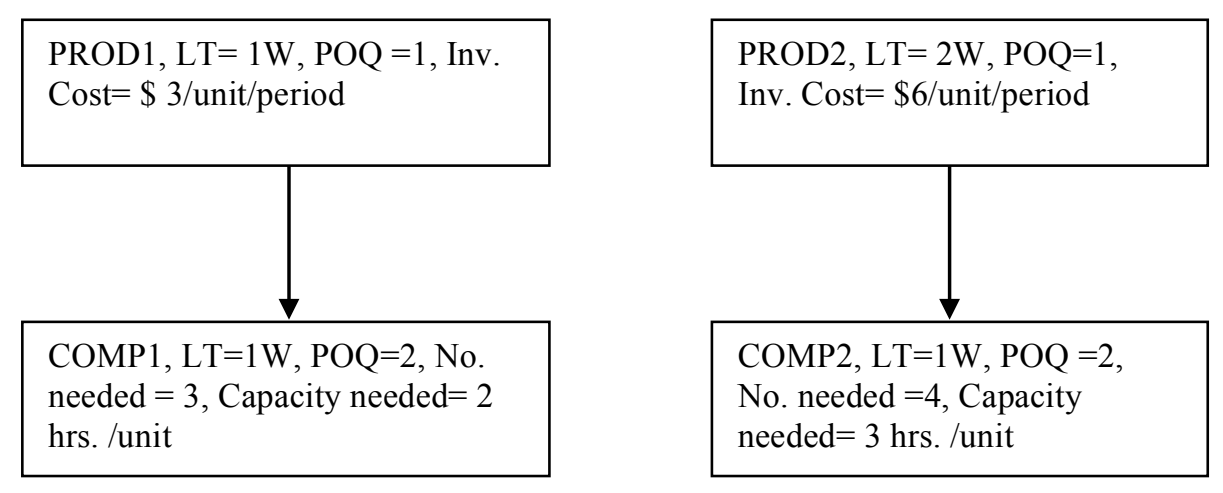

FIGURE 2. Bill of Materials and Material Master Data

Demand for the products in four periods after the planning fence is shown in Table 1. To keep the problem simple, it was assumed there is only resource, and its available capacity in each of the four periods is given in Table 1.

TABLE 1. Demand and Resources Data

\begin{tabular}{|l|l|l|l|l|}
\hline \multicolumn{5}{|c|}{ Demand Data } \\
\hline Week No. & 1 & 2 & 3 & 4 \\
\hline
\end{tabular}




\begin{tabular}{|l|l|l|l|l|}
\hline PROD1 & 25 & 30 & 40 & 30 \\
\hline PROD2 & 15 & 20 & 30 & 40 \\
\hline
\end{tabular}

\begin{tabular}{|l|l|l|l|l|}
\hline \multicolumn{5}{|c|}{ Resources Data } \\
\hline Week No. & 1 & 2 & 3 & 4 \\
\hline Available Capacity in hours & 1000 & 500 & 400 & 700 \\
\hline
\end{tabular}

Material requirements planning (MRP) is carried out with the bill of materials and inventory data shown above. MPS for the two products is calculated in terms of the variables. MRP calculations are shown in Table 2 below.

TABLE 2. Material Requirements Planning

\begin{tabular}{|c|c|c|c|c|c|c|c|c|c|c|c|c|c|}
\hline WEEK\# & -2 & -1 & 1 & 2 & 3 & 4 & -3 & -2 & -1 & 1 & 2 & 3 & 4 \\
\hline $\begin{array}{l}\text { Demand } \\
\text { Forecast }\end{array}$ & & & 25 & 30 & 40 & 30 & & & & 15 & 20 & 30 & 40 \\
\hline $\begin{array}{l}\text { Master } \\
\text { Schedule }\end{array}$ & & & $\mathrm{x} 1$ & $\mathrm{x} 2$ & $\mathrm{x} 3$ & $\mathrm{x} 4$ & & & & y1 & y2 & y3 & $\mathrm{y} 4$ \\
\hline $\begin{array}{l}\text { POR for } \\
\text { Assembly }\end{array}$ & & $\mathrm{x} 1$ & $\mathrm{x} 2$ & $\mathrm{x} 3$ & $\mathrm{x} 4$ & & & y1 & y2 & y3 & $\mathrm{y} 4$ & & \\
\hline $\begin{array}{l}\text { Gross } \\
\text { Requirements } \\
\text { for } \\
\text { component } \\
\end{array}$ & & $3 \times 1$ & $3 \times 2$ & $3 \times 3$ & $3 \times 4$ & & & $4 \mathrm{y} 1$ & $4 y 2$ & $4 y 3$ & $4 y 4$ & & \\
\hline $\begin{array}{l}\text { POR for } \\
\text { component }\end{array}$ & $3 \times 1+3 \times 2$ & & $3 \times 3+3 \times 4$ & & & & $4 \mathrm{y} 1$ & $4 y_{2}$ & $4 y 3$ & $4 y 4$ & & & \\
\hline $\begin{array}{l}\text { Capacity } \\
\text { Requirements }\end{array}$ & $6 \times 1+6 \times 2$ & & $6 \times 3+6 \times 4$ & & & & $12 \mathrm{y} 1$ & $12 \mathrm{y}^{2}$ & $12 \mathrm{y}^{3}$ & $12 \mathrm{y} 4$ & & & \\
\hline
\end{tabular}

The simultaneous decision model in the linear programming model given above can now be formulated. EXCELsolver was used for the formulation and the solution of the sample problem. The solution is shown in Table 3 below. In the sample problem, LP solution is attempting to minimize product inventories while finding an optimal solution within available capacity. POQ has already made the trade-off between setup cost and inventory cost for each item. The problem solution gives decisions on MPS, lot sizes in MRP, and capacity loads without the need for iterations amongst these decisions.

TABLE 3: EXCEL-Solver Solution for the Sample Problem

\section{Microsoft Excel 14.0 Answer Report}

Worksheet: [solver-sheet-1.xlsx]Sheet1

Report Created: 1/10/2013 11:39:22 AM

Result: Solver found a solution. All Constraints and optimality conditions are satisfied.

\section{Solver Engine}

Engine: Simplex LP

Solution Time: 0 Seconds. 
Iterations: 15 Subproblems: 0

\section{Solver Options}

Max Time $100 \mathrm{sec}$, Iterations 100, Precision 0.000001

Max Subproblems Unlimited, Max Integer Sols Unlimited, Integer Tolerance 5\%, Assume NonNegative

Objective Cell (Min)

\begin{tabular}{rrrr}
\hline Cell & Name & Original Value & \multicolumn{1}{c}{ Final Value } \\
\hline SV $\$ 19$ & & 0 & $\$ 215$ \\
\hline
\end{tabular}

Variable Cells

\begin{tabular}{|c|c|c|c|c|}
\hline Cell & Name & Original Value & Final Value & Integer \\
\hline \$F\$18 & PROD---PROD1 & 0 & 25 & Contin \\
\hline$\$ G \$ 18$ & PROD---PROD1 & 0 & 56.66666667 & Contin \\
\hline$\$ \mathrm{H} \$ 18$ & PROD---PROD1 & 0 & 13.33333333 & Contin \\
\hline \$I\$18 & PROD---PROD1 & 0 & 30 & Contin \\
\hline \$J\$18 & PROD---PROD2 & 0 & 34.16666667 & Contin \\
\hline$\$ K \$ 18$ & PROD---PROD2 & 0 & 0.833333333 & Contin \\
\hline \$L\$18 & PROD---PROD2 & 0 & 33.33333333 & Contin \\
\hline$\$ M \$ 18$ & PROD---PROD2 & 0 & 36.666666667 & Contin \\
\hline$\$ N \$ 18$ & End Inv ---PROD1 & 0 & 0 & Contin \\
\hline$\$ O \$ 18$ & End Inv ---PROD1 & 0 & 26.666666667 & Contin \\
\hline \$P\$18 & End Inv ---PROD1 & 0 & 0 & Contin \\
\hline \$Q\$18 & End Inv ---PROD1 & 0 & 0 & Contin \\
\hline \$R \$18 & End Inv ---PROD2 & 0 & 19.16666667 & Contin \\
\hline$\$ S \$ 18$ & End Inv ---PROD2 & 0 & 0 & Contin \\
\hline \$T\$18 & End Inv ---PROD2 & 0 & 3.333333333 & Contin \\
\hline \$U\$18 & End Inv ---PROD2 & 0 & 0 & Contin \\
\hline
\end{tabular}

Constraints

\begin{tabular}{|c|c|c|c|c|c|}
\hline Cell & Name & Cell Value & Formula & Status & Slack \\
\hline$\$ V \$ 20$ & Inv Bal Con. & 25 & $\$ V \$ 20=\$ W \$ 20$ & Binding & 0 \\
\hline \$V\$21 & Inv Bal Con. & 30 & $\$ V \$ 21=\$ W \$ 21$ & Binding & 0 \\
\hline$\$ V \$ 22$ & Inv Bal Con. & 40 & $\$ V \$ 22=\$ W \$ 22$ & Binding & 0 \\
\hline$\$ V \$ 23$ & Inv Bal Con. & 30 & $\$ V \$ 23=\$ W \$ 23$ & Binding & 0 \\
\hline \$V\$24 & Inv Bal Con. & 15 & $\$ V \$ 24=\$ W \$ 24$ & Binding & 0 \\
\hline \$V\$25 & Inv Bal Con. & 20 & $\$ V \$ 25=\$ W \$ 25$ & Binding & 0 \\
\hline \$V\$26 & Inv Bal Con. & 30 & $\$ V \$ 26=\$ W \$ 26$ & Binding & 0 \\
\hline \$V\$27 & Inv Bal Con. & 40 & $\$ V \$ 27=\$ W \$ 27$ & Binding & 0 \\
\hline \$V\$28 & Cap. Con.--period 1 & 410 & $\$ V \$ 28<=\$ W \$ 28$ & $\begin{array}{l}\text { Not } \\
\text { Binding }\end{array}$ & 590 \\
\hline$\$ V \$ 29$ & Cap. Con.--period 2 & 500 & $\$ V \$ 29<=\$ W \$ 29$ & Binding & 0 \\
\hline$\$ V \$ 30$ & Cap. Con.--period 3 & 400 & $\$ V \$ 30<=\$ W \$ 30$ & Binding & 0 \\
\hline
\end{tabular}




\begin{tabular}{|c|c|c|c|c|c|}
\hline$\$ V \$ 31$ & Cap. Con.--period 4 & 700 & $\$ V \$ 31<=\$ W \$ 31$ & Binding & 0 \\
\hline
\end{tabular}

The sample problem given above is intentionally simple to illustrate the main concept of the model, which is that material requirement planning can be carried out in terms of unknown variables of the master production schedule. In real life implementation, multi-level bills of materials, many products and many components, many work centers, setup time, and several types of capacity resources can all be incorporated easily.

\section{CONCLUSIONS}

The model proposed in this paper can help managers avoid time-consuming and costly iterative and feedback loop procedures when making MPS, MRP, and capacity requirements planning decisions because it allows managers to make these decisions simultaneously. However, in developing this model, some assumption were made relative to using the POQ method for calculating lot sizes; so further research may be needed to investigate the applicability of other lot-sizing methods. A sample problem was used to demonstrate the applicability of the model.

This simultaneous decision model can also be used to teach the theory and practice of MPS, MRP, and capacity requirements planning to students in supply chain management courses. This model will give students an understanding of current practice and will provide them with an understanding of how to make these important decisions.

\section{REFERENCES}

1. Berry, W. L. (1972). Lot Sizing Procedures for Requirements Planning Systems: A Framework for Analysis. Production and Inventory Management, 13(2), 1972, 19-34.

2. Jacobs. F.R., Berry, W.L., Whybark, D.C., and Vollmann, T.E. (2011). Manufacturing Planning and Control for Supply Chain Management. Sixth Edition, New York: Irwin/McGraw-Hill.

3. Orlicky, J. (1975) Material Requirements Planning. New York: McGraw-Hill.

4. SAP SCM Software On-line Documentation, Version 5.1. (2008).

5. Stevenson, W. J. (2012). Operations Management. Eleventh Edition, New York: Irwin/McGraw-Hill. 